Rheumatoid vasculitis (RV) is an extra-articular manifestation of rare but serious rheumatoid disease that involves the damage of small and medium sized vessels.

Objectives: The purpose of the study was to evaluate the incidence of damages occurred on cutaneous level in patients diagnosed with RA and to detect capillaroscopic microangiopathy changes in the activity of rheumatoid disease. Methods: 101 patients were included in the study, all were diagnosed with RA according to the ACR/EULAR 2010 criteria. RV diagnosis was based on the clinical examination. The capillaroscopic evaluation was performed with a 3.0 VideoCap device at a 200x magnification (200x magnification contact lenses). Capillaroscopic examination was performed on fingers II-V of both hands, being considered pathological if the capillaroscopic changes are present in at least two fingers. The activity of disease was calculated using DAS 28 ESR score.

Results: $18 \%$ of examined patients was male and $82 \%$ female, with the mean age of 56,2 years $\pm 10.16 S D$, and the mean duration of the disease in years of illness was $8.65 \pm 5.31$ SD. 3 patients had periungual vasculitis with cutaneous ulceration and gangrene, 12 patients had palpable purpura. $29 \%$ of the patients had vasospastic skin changes. The activity score of RA was associated with the capillaroscopic changes in peripheral microangiopathy $p-0.037$. Capillaries images were heterogenous in aspects and distribution, tortuous capillaries, microhemorrhages, giant/dilated capillaries, avascular areas were observed.

Conclusion: Vascular microangiopathy evidenced by capillaroscopic examination is present in patients with cutaneous vasculitis having a medium, severe activity of rheumatoid diseases.

References:

[1] Cutolo M, Paolino S, Smith V. Nailfold capillaroscopy in rheumatology: ready for daily use but care in terminology. Clinical Rheumatology 2019; 38:22932297 http://doi.org/10/s10067-019-04716-w

[2] Lambova N, Müller-Ladner U. Capillaroscopic pattern in inflammatory arthritis. Microvascular Research 2012; 83:318-322
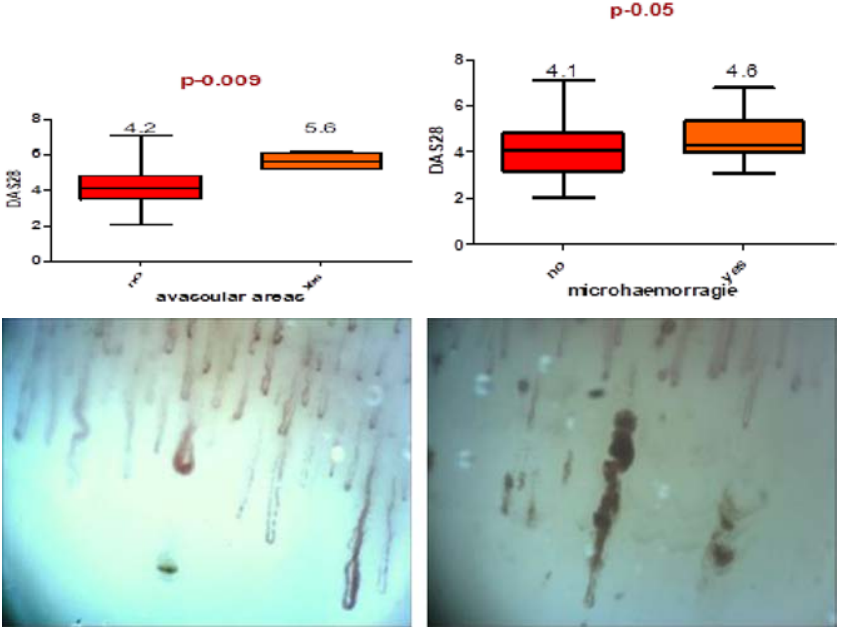

Dilated, giant capillaries, microhemorrhage bleedings, avascular area Reduced blood flow (observed in dynamics)

Disclosure of Interests: Mirela Parvu Speakers bureau: Not for this subject, theme, Anca Cozos Speakers bureau: Not for this subject, theme, Anna-Iuliana Biro Speakers bureau: Not for this subject, theme, Horatiu Valeriu Popoviciu Speakers bureau: Not for this subject, theme DOI: 10.1136/annrheumdis-2020-eular.6150

\section{AB0260 SARCOPENIA AND RHEUMATOID ARTHRITIS}

V. Povoroznyuk ${ }^{1}$, N. Dzerovych ${ }^{1}$, O. Ivanyk ${ }^{1}$, T. Karasevska ${ }^{2} .{ }^{1}$ D. F. Chebotarev Institute of Gerontology NAMS of Ukraine, Kyiv, Ukraine; ${ }^{2} \mathrm{O}$. Bogomolets National Medical University, Kyiv, Ukraine

Background: Nowadays in the field of syndromes and diseases associated with age, scientists focus especial attention on the problem of sarcopenia, which combines an increased risk of falls, deterioration of life quality, impaired functional activity, reduced life expectancy and increased mortality of patients. In 2016, sarcopenia has been included in the International Classification of Diseases. There are the primary and secondary forms of sarcopenia.

Objectives: The aim of this study was to evaluate the bone mineral density, lean mass, frequency of pre-sarcopenia and analyze correlation among the activity parameters, duration of the disease, life quality and lean mass indices in women with rheumatoid arthritis.

Methods: 461 women aged $40-87$ years (age $-57.17 \pm 0.71$ years) were exam ined, among them 71 patients with rheumatoid arthritis and 390 controls. We conducted the clinical and laboratory examination. Pain intensity was evaluated by the visual analogue scale, the quality of life - by the HAQ questionnaire. Lean mass, bone mineral density were measured by the X-ray absorptiometry (Prodigy, GEHC Lunar, Madison, WI, USA). Pre-sarcopenia was determined when an appendicula lean mass index was less than $5.72 \mathrm{~kg} / \mathrm{m} 2$ (V. Povoroznyuk, N. Dzerovych, 2016). Results: Patients with rheumatoid arthritis had a significantly lower femoral neck mineral density $(p=0.002)$, lean mass of the total body $(p=0.01)$ and appendicular lean mass $(p<0.01)$. We didn't find any significant connection among the activity parameters (C-reactive protein, ESR, pain VAS, DAS-28), duration of the disease, life quality and lean mass indices in patients with rheumatoid arthritis. However, a significant correlation was found between the number of swollen joints and lean mass of upper limbs $(r=0.67 ; p=0.02)$. The frequency of pre-sarcopenia in women with rheumatoid arthritis was $49 \%$, in the control group - $18 \%$. Conclusion: Patients with rheumatoid arthritis had not only bone tissue, but also skeletal muscle tissue disorders, resulting in a significant deterioration of functional capacity and quality of life. Given the significant medical and social significance of the problem, further studies into the mechanisms of pathogenesis, development of diagnostic methods, prevention and treatment of sarcopenia in patients with rheumatoid arthritis are required.

Disclosure of Interests: None declared DOI: 10.1136/annrheumdis-2020-eular.2727

\section{AB0261 IMPACT OF COMORBIDITIES IN THE DISEASE ACTIVITY OF PATIENTS WITH SPONDYLOARTHRITIS AND RHEUMATOID ARTHRITIS: TUNISIAN REGISTRY (BINAR)}

R. Tekaya ${ }^{1}$, L. Rouached ${ }^{1}$, A. Ben Tekaya ${ }^{1}$, O. Saidane ${ }^{1}$, S. Bouden ${ }^{1}$, I. Mahmoud ${ }^{1}$, S. Baklouti ${ }^{2}$, N. Bergaoui ${ }^{3}$, E. Bouajina ${ }^{4}$, M. Elleuch ${ }^{5}$, I. Gharsallah ${ }^{6}$, M. M. Kchir ${ }^{7}$, S. Kochbati ${ }^{8}$, A. Laatar ${ }^{9}$, Y. Mohamed ${ }^{10}$,

L. Abdelmoula ${ }^{1}$. ${ }^{1} \mathrm{Hospital}$ Charles Nicolle, Rheumatology, Tunis, Tunisia; ${ }^{2} \mathrm{Hedi}$ Chaker Hospital, Rheumatology, Sfax, Tunisia; ${ }^{3}$ Fattouma Bourguiba Hospital, Rheumatology, Monastir, Tunisia; ${ }^{4}$ Farhat Hached hospital, Rheumatology, Sousse, Tunisia; ${ }^{5}$ La Rabta, Rheumatology, Tunis, Tunisia; ${ }^{6}$ The Military Hospital in Tunis, Rheumatology, Tunis, Tunisia; ${ }^{7}$ Mohamed Kassab Institut, Rheumatology, Manouba, Tunisia; ${ }^{8} \mathrm{Hôpital} \mathrm{Habib} \mathrm{Thameur,} \mathrm{Rheumatology,}$ Tunis, Tunisia; ${ }^{9} \mathrm{Hop}$ ital Mongi Slim, Rheumatology, Marsa, Tunisia; ${ }^{10} \mathrm{Hospital}$ University Tahar Sfar, Rheumatology, Mahdia, Tunisia

Background: Comorbidities can be associated with rheumatoid arthritis (RA) and spondyloarthritis (SpA). This association can be fortuitous but can also be secondary to rheumatism itself or to the effects of the treatments used. These comorbidities can worsen the disease and even increase patient mortality.

Objectives: To assess the prevalence of comorbidities in RA or SpA patients from the Tunisian Blologics National Registry (BINAR) and to focus on their influence on the disease activity.

Methods: BINAR is a multicenter non-interventional and prospective study, conducted in Tunisia with 80 rheumatologists over a period of three years. It included patients with RA (ACR / EULAR 2010 criteria) or SpA (ASAS 2009 criteria). Data were collected and analyzed through an electronic platform managed by DACIMA. They included demographic data, smoking status and types of comorbidities (cardiovascular disease, diabetes, dyslipidemia, osteoporosis, high blood pressure (HBP), neoplasia, gastrointestinal ulcer, depression and fibromyalgia). RA activity was evaluated by the DAS28-VS score and SpA activity by the BASDAI and ASDAS-CRP scores.

Results: We included 298 patients (175 PR and $123 \mathrm{SpA}$ ) making the mean sex ratio 0.6 and mean age 49.18 years \pm 14.1 [18-79]. Mean $B M I$ was $27.0 \pm 5.5 \mathrm{~kg}$ $\mathrm{m}^{2}[15-45]$ and $17.7 \%$ of the patients were current smokers. Concerning disease activity, mean DAS28-VS in RA was at $4.9 \pm 1.5$ [1.1 - 8.1 and mean BASDAl and ASDAS-CRP, in SpA, were respectively $4.1 \pm 1.8$ and $2.8 \pm 1.1$. Comorbidities were noted in $54 \%$ of patients $(62.1 \%$ in SpA and $37.9 \%$ in RA), with an average of 1.7 comorbidities per patient.

The most common comorbidities were osteoporosis $(38.8 \%)$, cardiovascular disease $(20.1 \%)$, diabetes $(16.8 \%)$, HBP $(18.1 \%)$, dyslipidemia $(6.7 \%)$ and GIU $(6.0 \%)$. Depression, fibromyalgia and neoplasia were mentioned in $1.7 \%, 1 \%$ and $1 \%$, respectively.

No correlation was found between the number of comorbidities and the activity level of RA: DAS28-VS ( $p=0.12)$, nor the activity level of SpA: BASDAI $(p=0.07)$ ASDAS-CRP $(p=0.15)$. Correlations were studied between each comorbidity and activity disease parameters of RA and SpA, they are specified in Table 1. We found that only the presence of osteoporosis was associated with SpA activity, (ASDAS-CRP; $p=0.02$ ). 
Tableau $n^{\circ}$ 1: Relation between comorbidities and the disease activity parameters of rheumatoid arthritis and Spondyloarthritis

\begin{tabular}{lccc}
\hline & DAS 28 ESR & BASDAI & ASDAS CRP \\
\hline Diabetes & $\mathrm{p}=0.737$ & $\mathrm{p}=0.633$ & $\mathrm{p}=0.652$ \\
High Blood pressure & $\mathrm{p}=0.252$ & $\mathrm{p}=0.998$ & $\mathrm{p}=0.323$ \\
Obesity & $\mathrm{p}=0.565$ & $\mathrm{p}=0.585$ & $\mathrm{p}=0.904$ \\
Dyslipidemia & $\mathrm{p}=0.332$ & $\mathrm{p}=0.349$ & $\mathrm{p}=0.997$ \\
Osteoporosis & $\mathrm{p}=0.372$ & $\mathrm{p}=0.989$ & $\mathrm{p}=0.020$ \\
Gastrointestinal ulcer & $\mathrm{p}=0.829$ & $\mathrm{p}=0.286$ & $\mathrm{p}=0.910$
\end{tabular}

DAS: disease activity score; BASDAI: Bath Ankylosing Spondylitis Disease Activity Index; ASDAS: Ankylosing Spondylitis Disease Activity Score

Conclusion: According to this study, in patients with RA and SpA associated comorbidities may occur more frequently than expected (54\%). However, they had no relation to the activity of the disease according to their frequencies or their types, except osteoporosis which was significantly associated with the SpA activity. Identifying these comorbidities may affect the management and treatment decisions for these patients to ensure an optimal clinical outcome.

Acknowledgments: none

Disclosure of Interests: None declared

DOI: 10.1136/annrheumdis-2020-eular.3738

\section{AB0263 SEXUAL FUNCTION IN WOMEN WITH RHEUMATOID ARTHRITIS: A CASE-CONTROL STUDY.}

G. Serna-Peña ${ }^{1}$, S. M. Sánchez Romo ${ }^{1}$, O. Ilizaliturri Guerra ${ }^{1}$, A. Cárdenas ${ }^{1}$, D. Á. Galarza-Delgado ${ }^{1}$, J. C. López Zamarrón ${ }^{1} .{ }^{1}$ Hospital Universitario Dr. José Eleuterio González, Rheumatology, Monterrey, Mexico

Background: Sexual dysfunction is defined as a change in any component of sexual activity, which may cause frustration, pain and decreased sexual intercourse ${ }^{1}$. Rheumatoid arthritis (RA) is a systemic autoimmune disease, which may lead to decline in joint mobility, pain, and fatigue; these impairments may influence the sexual health of patients ${ }^{2}$.

Objectives: The main aim of this study is to determine if there is an altered sexual function in Mexican women with RA and compare if it occurs in a greater proportion than in healthy women.

Methods: A case-control study that included Mexican women between 18 and 65 years, with RA diagnosis (according to ACR/EULAR 2010 criteria) and age-matched controls was performed. Patients were excluded if they couldn't answer the questionnaires reliably or were currently pregnant. They were asked about their sexual activity in the last month, and the Arizona Sexual Experiences Scale (ASEX), Hospital Anxiety and Depression Scale (HADS) and Functional Assessment of Chronic Illness Therapy (FACIT) self-questionnaires were applied; disease activity was assessed by DAS-28. Variables were compared between groups with student $\mathrm{T}$ test for independent samples and chi-square.

Results: We included 102 RA patients and 101 controls. Baseline demographic characteristics between groups are shown in Table 1. Women with RA had less sexual activity than controls (48.03\% vs. $90.09 \%, p<0.001)$. Out of the total women included, the ASEX was applied only to those that had an active sex life, 49 with RA and 91 controls. Sexual dysfunction (> 18 points) was found in $55.1 \%$ of women with RA and in $52.74 \%$ of controls, with no significant differences $(p=0.860)$; the prevalence of severe fatigue was higher in RA than in the healthy group $(p=0.009)$ (Table 2$)$. Women with RA and sexual dysfunction had higher levels of anxiety $(p=0.024)$ and fatigue $(p=$ 0.008 ) than those with RA without sexual dysfunction; however, no significant difference was found in age, depression and level of disease activity between these groups.

Table 1. Comparison of demographic variables between groups.

\begin{tabular}{lccc}
\hline & $\begin{array}{c}\text { RA GROUP } \\
(\mathrm{n}=102)\end{array}$ & $\begin{array}{c}\text { CONTROL GROUP } \\
(\mathrm{n}=101)\end{array}$ & $\mathrm{P}^{*}$ \\
\hline Age, years $( \pm \mathrm{SD})$ & $52.98(+/-13.36)$ & $52.45(+/-8.34)$ & 0.738 \\
Sexual activity in the last month, $\mathrm{n}(\%)$ & $49(48.03 \%)$ & $91(90.09 \%)$ & $<0.001$ \\
Civil status & & & 0.456 \\
Single, $\mathrm{n}(\%)$ & $26(25.5 \%)$ & $18(17.82 \%)$ & \\
Married, $\mathrm{n}(\%)$ & $43(42.2 \%)$ & $55(54.45 \%)$ & \\
Divorced, $\mathrm{n}(\%)$ & $15(14.7 \%)$ & $11(10.89 \%)$ & \\
Domestic partnership, $\mathrm{n}(\%)$ & $5(4.9 \%)$ & $4(3.96 \%)$ & \\
Widowed, $\mathrm{n}(\%)$ & $13(12.7 \%)$ & $13(12.87 \%)$ & \\
Menopause, $\mathrm{n}(\%)$ & $70(68.6 \%)$ & $72(71.28 \%)$ & 0.760 \\
Has children, $\mathrm{n}(\%)$ & $88(86.3 \%)$ & $83(82.17 \%)$ & 0.447 \\
\hline
\end{tabular}

T de student or Chi-Square test according to type of variable
Table 2. Difference in means of survey scores and frequencies of abnormal scores between groups.

\begin{tabular}{lccc}
\hline & $\begin{array}{c}\text { RA GROUP } \\
(\mathrm{n}=49)\end{array}$ & $\begin{array}{c}\text { CONTROL GROUP } \\
(\mathrm{n}=91)\end{array}$ & $\mathrm{P}^{*}$ \\
\hline ASEX score $( \pm \mathrm{SD})$ & $15.65+/-4.82$ & $15.45+/-5.07$ & 0.819 \\
Sexual dysfunction, $\mathrm{n}(\%)$ & $27(55.1 \%)$ & $48(52.74 \%)$ & 0.860 \\
HADS-A, anxiety subscale $( \pm \mathrm{SD})$ & $6.53+/-3.95$ & $7.15+/-3.98$ & 0.378 \\
HADS- D, depression subscale $( \pm \mathrm{SD})$ & $5.34+/-4.12$ & $4.32+/-3.20$ & 0.108 \\
Fatigue score (FACIT) $( \pm \mathrm{SD})$ & $34.42+/-9.52$ & $39.21+/-8.37$ & $0.003^{*}$ \\
Severe fatigue symptoms, $\mathrm{n}(\%)$ & $17(34.69 \%)$ & $13(14.28 \%)$ & $0.009^{*}$
\end{tabular}

$\mathrm{T}$ de student or Chi-Square test according to type of variable

* Statistically significant difference.

High scores HADS, ASEX and low scores in FACIT indicate severity.

Conclusion: In this study, women with RA have less sexual activity than healthy women, but no greater sexual dysfunction. Patients with RA and sexual dysfunction have more anxiety and fatigue; but they have no difference in age, disease activity and depression than those with RA and normal sexual function.

References:

[1] Henrique P, Queiroz T, Almeida D, et al. Como o reumatologista pode orientar o paciente com artrite reumatoide sobre func, ão sexual. Rev Bras Reumatol. 2014;55(5):458-463.

[2] Zhao S, Li E, Wang J, Luo L, Luo J, Zhao Z. Rheumatoid Arthritis and Risk of Sexual Dysfunction: A Systematic Review and Metaanalysis. 2018;45(10).

Disclosure of Interests: None declared

DOI: 10.1136/annrheumdis-2020-eular.4035

\section{\begin{tabular}{|l|l}
\hline AB0264 ARTERIAL STIFFNESS IN RHEUMATOID ARTHRITIS \\
\hline
\end{tabular} PATIENTS AS A POTENTIAL PREDICTOR OF EARLY CARDIOVASCULAR AGEING AND} MORBIDITY

M. Schubertová ${ }^{1}$, A. Smržová ${ }^{1}$, P. Horak ${ }^{1}$, M. Skácelová ${ }^{1}$, E. Lokočová ${ }^{1}$,

Z. Heřmanová ${ }^{2}$, F. Mrázek ${ }^{2}{ }^{1}$ Palacky University Olomouc, University Hospital Olomouc, Department of Internal Medicine III - Nephrology, Rheumatology and Endocrinology, Olomouc, Czech Republic; ${ }^{2}$ Palacky University Olomouc, University Hospital Olomouc, Department of immunology, Olomouc, Czech Republic

Background: Cardiovascular disease (CVD) is one of the most common causes of death in Rheumatoid arthritis patients. Increased arterial stiffness is considered as an independent risk factor of development CVD and a predictor of all-cause morbidity and mortality. Increased arterial stiffness, due to premature vascular ageing, can be observed in patients with chronic inflammatory diseases as well as in RA patients.

Objectives: To evaluate arterial stiffness determined as carotid - femoral pulse wave velocity in rheumatoid arthritis patients. The comparison of traditional and nontraditional risk factor of CVD, disease activity and laboratory findings connected with subclinical atherosclerotic changes.

Methods: We evaluated data of 50 patients with rheumatoid arthritis (39 females, 11 male, mean age 57 , mean duration of disease of $13 y e a r s)$. The arterial stiffness, measured as carotid - femoral pulse wave velocity (PWV), was established with the SphygmoCor system. This non-invasive technique uses the principle of applanation tonometry. Our control group counted 25 heathy male and females with no history of CVD or autoimmune disease. We evaluated the influence of traditional risk factors for CVD as age, smoking, BMI, lipid profile, diabetes mellitus, history of $\mathrm{CV}$ and cerebrovascular morbidity to PWV in RA patients. Non-traditional risk factors contained Adiponectin, Fetuin A, Endothelin-1 and Asymmetric dimethylarginine. To measure disease activity was used DAS 28 and inflammatory parameters as a marker of current disease activity. For chronic changes was used X-ray of small joints. Results were correlated with PWV and statistically evaluated.

Results: Mean PWV in Rheumatoid arthritis patients was significantly higher $(9.7 \mathrm{~m} / \mathrm{s})$ than that in healthy control group $(6.7 \mathrm{~m} / \mathrm{s}) .49 \%$ of RA patients $(\mathrm{n}=$ 24 ) had increased arterial stiffness according to their age. $32 \%$ patients $(n=16)$ with PWV over $10 \mathrm{~m} / \mathrm{s}$ that indicates aortal function alteration. We didn't find correlation between arterial stiffness and traditional and non-traditional CVD risk factors. Increased PWV was not associated with high disease activity. Patients with higher arterial stiffness according to their age had longer RA history, higher level of rheumatoid factor, were more frequently anti-citrullinated protein antibodies (ACPA) negative and were more frequently treated with biological therapy. 